\title{
EDUCAÇÃO EM SAÚDE NO SERVIÇO DE RADIOLOGIA: ORIENTAÇÕES PARA PUNÇÃO ASPIRATIVA DE MAMA E TIREÓIDEA
}

\author{
Ivone ROSINI ${ }^{\mathrm{b}}$, Nádia Chiodelli SALUM
}

\section{RESUMO}

Trata-se de pesquisa convergente assistencial desenvolvida no Serviço de Radiologia de hospital-escola, cujo objetivo é conhecer as expectativas e dúvidas dos clientes submetidos à Punção Aspirativa por Agulha Fina de mama e tireoide. A coleta de dados ocorreu de setembro de 2010 a abril de 2011 , por meio de 10 encontros educativos em sala de espera e entrevistas com 88 clientes. Os resultados apresentam: percepção dos clientes em face do exame, o câncer como estigma e a educação em saúde como estratégia de enfrentamento. Revelaram também presença de sentimento de medo do procedimento e do diagnóstico de câncer. A prática educativa em sala de espera é um espaço que minimiza a ansiedade e permite a troca de experiências e conhecimentos entre profissional e cliente, bem como favorece uma rede de apoio entre os clientes. Caracteriza-se como espaço importante de atuação do enfermeiro no Serviço de Radiologia.

Descritores: Educação em saúde. Biópsia por agulha fina. Enfermagem.

\section{RESUMEN}

Una investigación convergente asistencial desarrollada en el Servicio de Radiología del hospital docente, cuyo objetivo es conocer las dudas y expectativas de los clientes sometidos a la Punción Aspirativa por Aguja Fina de mama y tiroides. La recolección de datos se realizó desde setiembre de 2010 hasta abril de 2011, por medio de 10 encuentros educativos con formato de sala de espera y entrevistas con 88 clientes. Los resultados revelaron: la percepción de clientes antes del examen, cáncer como estigma y educación para la salud como una estrategia para confrontación. Además, se revelaron el miedo tanto al procedimiento como al diagnóstico. La práctica educativa en la sala de espera es un espacio privilegiado para disminuir la ansiedad y permite una red de apoyo entre los clientes y un campo importante para la enfermera en el servicio de radiología.

Descriptores: Educación en salud. Biopsia con aguja fina. Enfermería.

Título: Educación en Salud en el Servicio de Radiología: orientaciones para punción de mama y tiroides.

\section{ABSTRACT}

This is a convergent care research developed in a school hospital's radiology service whose purpose is to learn about the concerns and expectations of clients submitted to breast and thyroid Fine Needle Aspiration Puncture. Data collection was conducted from September 2010 to April 2011 , through 10 educational meetings in the waiting room interviewing 88 clients. The results show: clients' perception of the test, cancer as a stigma and healthcare education as a confrontation strategy. In addition, they revealed fear of both the procedure and the diagnosis of cancer. Educational practice in the waiting room is a space to decrease anxiety and allows the exchange of experiences and knowledge between professional and client, it also fosters a support network among clients. It is characterized as important space of action to the nurse within radiology service.

Descriptors: Health education. Fine-needle biopsy. Nursing.

Title: Health education in radiology service: orientations for breast and thyroid aspiration puncture.

\footnotetext{
a Texto extraído da Dissertação de Mestrado Profissional Gestão do Cuidado em Enfermagem "Protocolo de cuidados a clientes submetidos ä punção aspirativa por agulha fina de mama e tireóide”.

b Mestre do Programa de Pós Graduação do Departamento de Enfermagem da Universidade Federal de Santa Catarina (UFSC) - Mestrado Profissional em Gestão do Cuidado. Enfermeira do Serviço de Radiologia do Hospital Universitário/UFSC

c Doutora em Filosofia da Enfermagem. Professora do Programa de Pós Graduação do Departamento de Enfermagem/UFSC - Mestrado

Profissional em Gestão do Cuidado. Membro do Grupo de Pesquisa, Enfermeira Coordenadora do Centro de Educação e Pesquisa em Enfermagem do Hospital Universitário/UFSC.
} 


\section{INTRODUÇÃO}

O adoecimento por câncer é acompanhado por inúmeras representações de ordem biopsicossocial em virtude da evolução e prognóstico da doença. As estimativas demonstram aumento progressivo de casos novos de câncer diagnosticados anualmente em âmbito mundial. No Brasil é estimado, para 2010 e 2011, a ocorrência do expressivo número de 489.270 novos $\operatorname{casos}^{(1)}$.

Dentre os diversos tipos de câncer no Brasil, o câncer de mama é o mais comum e a primeira causa de morte entre as mulheres, com risco estimado de 49 casos novos para 100.000 habitantes em $2010^{(1)}$. $\mathrm{O}$ câncer de tireoide não apresenta incidência tão significativa, entretanto, o índice no Brasil em 2006, aponta os percentuais de $1,16 \%$ casos novos para homens, e 5,27\%, para mulheres, assinalando o aumento nas taxas de incidência, principalmente nas mulheres ${ }^{(2)}$.

A magnitude do problema do câncer tem despertado a atenção da Organização Mundial de Saúde (OMS) no sentido de recomendar que a doença seja encarada como problema de saúde pública, focalizando suas ações estratégicas prioritariamente nas áreas de promoção, prevenção e diagnóstico precoce e entre elas a garantia de acessibilidade do cliente aos serviços de saúde para a definição diagnóstica, em casos suspeitos ${ }^{(1)}$ e a detecção precoce de lesões pré-cancerígenas ou doença em estágio inicial, com a realização de biópsia da área com alteração ${ }^{(1,3)}$.

A identificação de nódulo, palpável ou não, em mama e tireoide, tem como recomendação mundial a realização da Punção Aspirativa por Agulha Fina (PAAF) para elucidação diagnóstica precoce e subsídio do planejamento terapêutico ${ }^{(4-6)}$. A PAAF é conceituada como a remoção de material obtido por uma agulha transdérmica, inserida numa região específica, num órgão ou tecido, para posterior análise $\mathrm{e}^{(7)}$. O exame é reconhecidamente, um procedimento eficaz para diagnóstico citopatológico de lesões de mama e tireoide, utilizado por ter uma boa relação custo/benefício e possibilitar a determinação terapêutica, indicando a realização de biópsias de nódulos maiores de $1 \mathrm{~cm}$ ou com imagem suspeita ${ }^{(4-6)}$.

O Serviço de Radiologia do Hospital Universitário é credenciado como um dos prestadores do procedimento de PAAF de mama e tireóide no Estado. Observa-se, na prática, que o cliente é agendado e encaminhado para a realização do procedimento pelo médico, mas não recebe as orientações referentes ao exame propriamente dito. Favorece, dessa forma, que o mesmo chegue à Instituição, na maioria das vezes, com pouca ou nenhuma informação a respeito de como o exame, é realizado. Tal prática de saúde tem se mostrado pouco efetiva para atender às necessidades de cuidado à saúde a estes clientes, percebendo-se a vulnerabilidade emocional com que ingressam ao setor, o que justifica a necessidade de acolhimento e produção de atos de saúde voltados a esse grupo.

Diante desse cenário, e ao reconhecer as dificuldades enfrentadas pelos clientes, sentiu-se a necessidade de estabelecer um processo dialógico de escuta sensível anterior ao exame com o intuito de orientar e minimizar a ansiedade dos clientes. A educação em saúde é apontada como importante estratégia quando empregada de forma a estimular o processo de reflexão crítica e adoção de padrões de vida sadios para si e para a coletividade. Nesse sentido, o estudo teve como objetivo conhecer as expectativas e dúvidas dos clientes submetidos à PAAF de mama e tireoide.

\section{METODOLOLOGIA}

Trata-se de pesquisa Convergente Assistencial de abordagem qualitativa desenvolvida no Serviço de Radiologia de um hospital de ensino, no período de setembro de 2010 a abril de 2011 . O estudo totalizou 88 clientes. Estes foram previamente agendados por meio do Sistema de Regulação de Consultas da Secretaria do Estado de Saúde, ou no próprio hospital, totalizando 15 vagas semanais de PAAF de tireóide e/ou mama, independentemente. A coleta de dados foi realizada em 10 encontros educativos na modalidade sala de espera com a participação em média de 8 pacientes por encontro e entrevista semi-estruturada realizada após a realização da PAAF. Os encontros aconteceram em momentos únicos, às quartas-feiras, dia em que são realizadas as PAAFs na Instituição, no momento que antecede a execução do exame. A sala de espera tem o objetivo de propiciar espaços de compartilhamento de informações, estabelecer interação e troca de saberes, fixando-se como uma ferramenta utilizada nos Serviços de Saúde para promover o processo reflexivo e de co-responsabilidade ${ }^{(3)}$.

Considerando que os grupos eram diferenciados em relação a gênero, faixa etária, necessidades biológicas e sociais, os encontros foram adaptados ao perfil de cada grupo, seguindo a lógica de co- 
nhecer as percepções dos clientes frente à PAAF. As falas foram gravadas e, posteriormente, transcritas, com complementação de memória recente, quanto à comunicação não verbal, posteriormente analisados em categorias temáticas ${ }^{(8)}$. A inclusão dos clientes nos grupos se deu por livre demanda após sua apresentação junto ao guichê de recepção para entrega dos documentos, momento em que foram convidados a participar do encontro.

Os encontros foram organizados em três momentos: acolhimento e apresentação, orientações pertinentes ao exame de PAAF e avaliação do momento vivido. $\mathrm{O}$ acolhimento, foi organizado de forma a buscar a inclusão e o reconhecimento do grupo. Foi utilizada como estratégia a apresentação individual do participante e, em seguida, para estimular a verbalização das expectativas e dúvidas em relação ao exame, foram convidados a escolher, dentre figuras expostas de paisagens, animais, pessoas e objetos, a que melhor expressasse seus sentimentos perante a realização do exame. Desta forma favoreceu-se maior descontração e conhecimento do grupo. Na sequência, foram estimulados a verbalizar suas expectativas e dúvidas, guiadas pelas questões de reflexão: Quais suas expectativas em relação à realização da punção? Quais as dúvidas que você tem para a realização do exame?

A partir dos questionamentos externados gerou-se um momento de discussão interativa, buscando a elucidação e reafirmação dos posicionamentos assertivos por meio de orientações pertinentes ao procedimento. Os clientes foram identificados pela letra "P", seguida do número de ordem das entrevistas ( $\mathrm{P} 1, \mathrm{P} 2, \ldots, \mathrm{P} 88)$. $\mathrm{O}$ agrupamento dos dados dos encontros possibilitou a formulação de três categorias de análise: expectativas acerca do exame; o estigma do câncer; e a Educação em Saúde como estratégia para o enfrentamento.

A Resolução 196/96 do Conselho Nacional de Saúde ${ }^{(9)}$ foi tomada como referência no que tange aos aspectos éticos e assinatura do Termo de Consentimento Livre Esclarecido (TCLE). A pesquisa foi submetida ao Comitê de Ética em Pesquisa com Seres Humanos/UFSC aprovado conforme protocolo $n^{\circ}$ 1017/10.

\section{RESULTADOS E DISCUSSÃO DOS DADOS}

O perfil dos integrantes da pesquisa aponta $100 \%$ dos clientes submetidos à PAAF de mama $\mathrm{e}$ tireoide na Instituição são provenientes de diversas regiões do Estado de Santa Catarina, com histórias e experiências de vida e profissional diversificadas. Constata-se que a maioria é da grande Florianópolis, com $48 \%$; a região Sul $17 \%$; a região Oeste, $11 \%$; a região Norte, $10 \%$; Vale do Itajaí, $9 \%$; e região Serrana, 3\%. Essa amostragem ratifica o Convênio firmado entre a Secretaria de Estado da Saúde (SES) e o HU em 2004, que certifica o HU como referência em exames de média/alta complexidade, dentre eles, a PAAF, em âmbito estadual.

Dos 88 participantes, 79 eram do sexo feminino e 9, do sexo masculino. A faixa etária revela idade entre 17 e 84 anos, com predominância entre 50 e 70 anos.

Em relação ao acesso para agendamento, 53\% das PAAF ocorreu através do setor de alto custo da SES, pelo SISREG e 47\% no Serviço de Radiologia do HU. Em relação ao órgão a ser puncionado, observa-se que as biópsias de tireoide representam $88 \%$ das solicitações, enquanto que as de mama correspondem $12 \%$.

A crescente demanda de biópsias de tireoide tem relação com à identificação precoce de cistos e nódulos pela busca ativa, evolução tecnológica de exames por imagens e a interação entre as especialidades médicas ${ }^{(10-11)}$, realizada por meio de exame físico e de ultrassonografia.

Apesar do estudo ter identificado as PAAFs de mama em menor número, os dados apontam que o câncer de mama é o tipo mais comum entre as mulheres e o segundo mais frequente em todo o mundo. A demanda na realização de biópsias de mama está sendo realizada por meio de core biopsya e estereotaxia, realizada com o auxílio de ultrassom e mamógrafo, consistindo-se na técnica mais eficaz para o câncer de mama.

\section{Expectativas dos clientes frente ao exame}

As expectativas dos clientes frente a realização da PAAF foram vivenciadas e manifestadas diferentemente por cada um, os quais evidenciam as subjetividades presentes no diálogo entre pesquisadora e clientes, por meio da escuta sensível e ativa. A manifestação dos sentimentos pode ser observada pelo acolhimento do grupo, que ocorreu de forma lúdica, instigando-os a expressarem anseios e dúvidas em relação à realização do exame.

[...] hoje eu me sinto assim, comendo uma pimenta porque eu já passei por tanto! Então eu me sinto como 
se eu estivesse comendo uma pimenta daquelas bem braba [apontando para a figura de uma mulher com uma pimenta na boca] (P 29).

Dispor de instantes para refletir a respeito do momento vivido permite entrar em contato consigo e se perceber. Esses sentimentos puderam ser expressos conforme a fala de P67, que se manteve emocionada e calada durante todo o encontro e, somente após a realização do exame, na entrevista individual, conseguiu verbalizar seus sentimentos:

[...] quem não gosta de falar, chora! Eu aproveito se tem alguém chorando. Eu tava presa, me sinto sozinha. Sabe por que eu tirei aquela figura? [lembrando a figura de uma senhora à beira de uma estrada de ferro com uma enxada nas mãos, uma foto antiga que lembra a época da guerra]. [...] Depois que eu retirei a figura é que vi que ela tava com uma enxada nas mãos, é a minha luta. (P 67).

O emprego das figuras estimulou-os a repensar e expressar seus sentimentos com vistas a minimizar a angústia e a ansiedade próprias da expectativa de realizar um exame que pode alterar seu processo de viver. Muitos participantes aproveitaram o encontro e conseguiram perceber-se, dando vazão aos seus sentimentos, descobrindo nas figuras, potencialidades para o enfrentamento do momento.

Em relação a manifestação de sentimentos foi possível identificar sentimento de medo relacionado ao procedimento e sentimento de medo relacionado ao diagnóstico.

O medo é conceituado como "perturbação resultante da ideia de um perigo real ou aparente ou da presença de alguma coisa estranha ou perigosa; pavor, susto, terror, apreensão"(12). Esse sentimento de perigo real ou apreensão manifestou-se de diversas formas, por meio de gestos, choro, risos, expressões faciais e verbais, silêncio e depoimentos simples, que explicitaram suas preocupações com o futuro diante de um resultado positivo.

Eu estou apreensiva com relação ao procedimento, ao resultado. Eu não sei se tem anestesia ou se não tem. Se é agulhada ou é cortado, é tudo uma mistura! Essa noite eu só vaguei, eu não dormi (P77).

Percebe-se que a acepção do medo toma vulto no momento em que ocorre uma correlação entre o exame que irão realizar e o provável diagnóstico de câncer.
A ausência de orientação ou a inadequação das informações sobre o procedimento produziu reações prejudiciais ao cliente. As informações obtidas junto à comunidade, repassadas por alguém que já vivenciou o exame, trazem em seu bojo as percepções pessoais da experiência vivida, seja de forma positiva ou negativa, transferindo para si a forma como o exame foi vivenciado por outras pessoas.

Eles falaram: esse exame que tu vais fazer é biópsia, eles vão tirar com agulha um líquido, isso dói porque depois tu te sentes mal, não sei o que lá, não sei o que lá. Eu penso assim, se eu tenho que enfrentar eu enfrento, mas estou assustada, meu medo é muito grande (P38).

Sob esse aspecto é importante valorizar o conhecimento prévio do sujeito, bem como reconhecer as formas que assume o processo saúde/doença para cada um deles.

Observou-se ansiedade relacionado ao medo do exame e da forma como este seria realizado, se haveria ou não anestesia, se haveria corte do nódulo.

O medo da dor relatado é um fator causador de estresse para a maioria deles. A interpretação dos fatores que causam estresse é pessoal, e está relacionado à forma com que cada indivíduo se mobiliza para o enfrentamento da situação vivenciada, cabendo-lhe a responsabilidade de avaliar e definir quais recursos utilizará para superar cada situação estressante vivida ${ }^{(13)}$.

A dor é definida como "uma experiência sensorial e emocional desagradável associada a dano tecidual real ou potencial ou descrita em termos que sugerem tal dano" ${ }^{(14)}$. Constitui-se, uma experiência privada e subjetiva, que integra também fatores emocionais e culturais individuais.

Outro aspecto destacado é a ansiedade manifestada em relação ao resultado/diagnóstico que esse exame possa revelar:

[…] minha preocupação não é o dia de hoje, pode me virar do avesso. É o amanhã, é com o resultado que pode vir (P76).

Os temores do procedimento e do diagnóstico apresentam causas diversas, dentre elas, a falta de informações adequadas sobre o exame e as possibilidades terapêuticas, uma vez que o câncer é visto como um grande flagelo para a sociedade em virtude do sofrimento, mutilações e comprometimento das relações afetivas e sociais que traz para a pessoa e sua família ${ }^{(15)}$. Nesse aspecto, a entrevista confirmou 
sua importância enquanto técnica por oportunizar o apoio e a interação profissional x cliente.

\section{Câncer como estigma}

Em relação às dúvidas apresentadas pelos clientes muitas tem relação com o estigma que o câncer gera. O câncer é considerado uma doença incurável e estigmatizante, que acarreta sentimentos negativos, desde o diagnóstico até o tratamento e prognóstico, pois traz consigo sofrimento e o medo iminente da morte ${ }^{(16)}$. Observou-se que a palavra câncer foi pouco mencionada em todos os encontros. Havia um acordo velado e praticamente ninguém a usava. Ao falar sobre as dúvidas, estas se concentravam no diagnóstico que este exame ocasionaria suas consequências e limitações, referiam-se ao mesmo com os termos positivo ou negativo, doença, benigno ou maligno, conforme nos mostra a fala:

Eu já tive caso na família, a ansiedade é maior ainda. Minha irmã, eu vi todo o sofrimento dela. Tenho medo de ser maligno e passar por tudo o que ela passou (P4).

O câncer é considerado uma doença complexa sendo vista por muito tempo como doença ligada ao poder maligno, de comportamento destruidor do corpo ${ }^{(17)}$. Na atualidade, com toda a tecnologia a serviço da saúde trazendo boas perspectivas de cura, a possibilidade de adoecer com câncer, traz em seu bojo um longo caminho a ser percorrido, com exames frequentes, tratamentos invasivos além da ansiedade frente à incerteza da efetividade da terapêutica e do afastamento de familiares pelas longas internações. Poucos foram os clientes que se referiram ao câncer de forma explícita. A maioria que o fez, possuía uma experiência muito próxima de familiar ou amigo acometido pela doença, o que o habilitava a falar de forma aberta, independente dessa experiência ser positiva ou negativa:

[...] eu tive uma amiga que teve câncer e me contava tudo, inclusive das reuniões de apoio. [...] se for aquela doença que ninguém di o nome, e diz que é um castigo, mas não é um castigo, é uma doença que é o câncer. Eu vou ter que enfrentar (P43).

Observou-se também que a fé em Deus e a espiritualidade independente da religião, foi vinculada à esperança e crença na possibilidade de lutar contra a doença e suportar o sofrimento.

\section{Educação em saúde como estratégia de enfrentamento}

A Educação em Saúde tem sido proposta com a perspectiva de desenvolver no cliente o pensamento “crítico/reflexivo sobre a realidade", possibilitando a instrumentalização necessária para transformar o status quo e promover mudanças para melhorar as condições de vida saudáveis ${ }^{(18)}$.

$\mathrm{O}$ encontro, enquanto espaço educativo de livre expressão e interação, possibilitou, além da aprendizagem, a reflexão sobre si mesmo, a percepção do outro e a troca de experiências e vivências. A potencialidade da educação em saúde de gerar transformações depende de como as ações educativas são concebidas e desenvolvidas e de que proveito os indivíduos fazem dela.

[...] enquanto fiquei esperando me deu cólica. [...] antes da palestra eu tava "bombada". Depois, eu fiquei tranquila. A gente vem leiga 90\%. O médico não disse nada. Eu não dormi essa noite, fiquei muito tensa (P77).

As ações educativas devem ser pautadas sob a perspectiva de instigar no cliente a reflexão sobre seu processo de vida, instrumentalizando-o a concretizar as mudanças comportamentais necessárias para a obtenção de uma melhor qualidade de vida ${ }^{(18)}$

Apesar da sala de espera ser um espaço para tirar dúvidas e compartilhar ansiedades e saberes, alguns clientes relataram que a princípio o convite para participar da sala de espera provocou apreensão. Ficaram impactados, associando à gravidade do caso, conforme mostra a afirmação:

No início foi meio assustador, o que está acontecendo? O fato de chamar para uma sala não é normal, chamar quando a gente vai fazer um exame! Fiquei confuso, inicialmente (P9).

Recomendam que o convite seja feito na recepção, quando da entrega dos formulários, deixando clara sua intencionalidade, assim, atenua a ansiedade gerada nos minutos transcorridos entre o convite e o início do encontro. Afirmam que as orientações foram oportunas e auxiliaram a integração do grupo, promovendo a troca de experiências e solidariedade num momento de tanta fragilidade.

[...] da outra vez eu fui chorando para casa porque doeu muito. Hoje, não tô sentindo nada. O encontro foi ótimo, nos ajudou a ficar mais sossegada, pelo menos 
pra mim. Porque eu achei que ia sentir dor como antes. Eu nunca tive um encontro assim antes, me ajudou a perder o medo (P87).

A Política Nacional de Humanização, tem defendido a preocupação com o acolhimento do cliente, enfatizando "a responsabilização do trabalhador/ equipe pelo cliente, desde a sua chegada até a sua saída”(3). Estabelece que acolher é receber bem, com atenção e disponibilidade para escutar e valorizar as particularidades de cada caso, estabelecendo uma ação humanizada ${ }^{(3)}$.

A prática educativa realizada em sala de espera estabeleceu uma conduta de acolhimento por meio de escuta sensível e solidária respeitando as necessidades individuais.

Outro aspecto presente nas falas dos clientes aponta que a troca de experiências na sala de espera propiciou o auxílio mútuo, criando uma rede de apoio, principalmente por vivenciarem a mesma situação, em que as dúvidas são sanadas de forma interativa e dialógica, pautada na escuta sensível:

Nós ficamos nos apoiando uma à outra [...] mesmo que o paciente fale com os médicos, não é a mesma coisa, não tem o mesmo carinho, a mesma atenção. Conversar, explicar, dizer que tá torcendo (P4).

Nesta perspectiva , a sala de espera é: [...] espaço privilegiado para a constituição de rede de apoio, estabelecimento e ampliação de vínculos afetivos; reflexão e conscientização das determinações do processo saúde-doença; organização e mobilização para o efetivo controle social, bem como espaço de ensino-aprendizagem, orientação, intervenção e educação em saúde, efeitos do empowerment comunitário proporcionado ${ }^{(19)}$.

As manifestações demonstraram que as ações desenvolvidas durante a trajetória do cliente no Setor de Radiologia protagonizaram ações assertivas com vistas ao cumprimento da Política Nacional de Humanização ${ }^{(3)}$, que assegura ao cliente um atendimento efetivo para a solução de seus problemas de saúde ${ }^{(3,20)}$.

A prática educativa possibilita ao enfermeiro do Serviço de Radiologia atuar sob o aspecto da educação crítica e transformadora, construindo, em conjunto com o cliente, um momento de reflexão e discussão acerca da circunstância vivenciada, demonstrando ser uma estratégia adequada para a abordagem desses clientes.

\section{CONSIDERAÇÕES FINAIS}

Em seus muitos aspectos, a educação em saúde é uma estratégia que aproxima o cliente do profissional de saúde na perspectiva de troca de saberes e realização de um cuidado humanizado. A sala de espera como estratégia educativa favorece o compartilhamento de dúvidas e minimiza a ansiedade presente antes do exame. Justifica-se a relevância do estudo por ser um campo de atuação do enfermeiro no Serviço de Radiologia pouco explorado e que vem crescendo por conta do grande número de caso de câncer identificados mundialmente, sinalizando a necessidade de ampliar ações educativas que preparem os clientes para a exploração diagnóstica.

Possibilitou ao enfermeiro refletir acerca dos sentimentos dos clientes submetidos à PAAF de mama e tireoide com vistas a minimizar a ansiedade presente nesse momento. Nesse sentido, foi possível identificar, nos clientes, o medo relacionado ao procedimento e, o medo associado a possibilidade do diagnóstico de câncer. A livre expressão de sentimentos e percepções permitiu a formação da rede de apoio entre os clientes que procuram, nesse momento de fragilidade, ajudar-se mutuamente com palavras de conforto e alento.

A implementação dessa prática pelo enfermeiro no Serviço de Radiologia, alicerça e reorienta toda a atenção à saúde com vistas a promover um ensino que se aproxime das necessidades de saúde dos clientes, conhecendo, reconhecendo e respeitando seus valores, experiências e conhecimentos, constituindo-se em um espaço para educar e cuidar, estabelecendo articulação entre as diferentes dimensões do fazer do enfermeiro.

\section{REFERÊNCIAS}

1 Instituto Nacional de Câncer (BR). Estimativa 2010: incidência do câncer no Brasil [Internet ]. Rio de Janeiro: INCA; 2009 [citado 2011 Ago 23]. Disponível em: http://www.inca.gov.br/estimativa/2010/index. asp?link=conteudo_view.asp\&ID=2.

2 Brito AS, Coeli CM, Barbosa FS, Caetano R, Santos MO, Vaisman M. Estimativa da incidência do câncer de tireoide no Brasil: uma abordagem por meio de modelos polinomiais Cad Saúde Pública. 201 1;27(7):1441-44.

3 Ministério da Saúde (MS), Secretaria de Atenção a Saúde, Núcleo Técnico da Política Nacional de Humanização. Humaniza SUS: documento base para gestores 
e trabalhadores do SUS [Internet]. $4^{\mathrm{a}}$ ed. Brasília (DF): MS; 2009 [citado 2011 Ago 26]. Disponível em: www. nescon.medicina.ufmg.br/biblioteca/imagem/0259.pdf.

4 Camargo RYA, Tomimri EK, Knobel M, Medeiros Neto G. Avaliação preoperatória de nódulos thireóides: papel da ultrassonografia e da biópsia de aspiração por agulha fina, seguida de citologia. Clinics [Internet]. 2007 [citado 2010 Ago 26];62(4):41 1-8. Disponível em: http:// www.scielo.br/pdf/clin/v62n4/a07v62n4.pdf.

5 Maia AL, Ward LS, Carvalho GA, Graf H, Maciel RMB, Maciel LMZ, et al. Nódulos de tireoide e câncer diferenciado de tireoide: consenso brasileiro. Arq Bras Endocrinol Metab. 2007;51(5):867-93.

6 Karimzadeh M, Sauer T. Diagnostic accuracy of fine-needle aspiration cytology in histological grade 1 breast carcinomas: are we good enough? Cytopathology. 2008;19(5):279-86.

7 Kemp C, Lima GR. Punção por agulha fina. In: Piato S. Mastologia. São Paulo: Roca; 1995. p. 1099.

8 Minayo MCS, organizadora. Pesquisa social: teoria, método e criatividade. Rio de Janeiro: Vozes; 2000.

9 Ministério da Saúde (BR). Resolução 196, de 10 de outubro de 1996. estabelece critérios sobre pesquisa envolvendo seres humanos [Internet]. Brasília (DF): Conselho Nacional de Saúde; 1996 [citado 2011 Jul 14]. Disponível em http://conselho.saude.gov.br/ Resolucoes/1996/Reso196.doc.

10 Choi YJ, Park YL, Koh JH. Prevalence of thyroid cancer at a medical screening center: pathological features of screen-detected thyroid carcinomas. Yonsei Med. 2008;49(5):748-56.

11 Nemetz MA, Nemetz AB, Santos MB. Carcinoma papilífero de glândula tireoide: uma análise retrospectiva de 52 casos. Rev Bras Cir Cabeça Pescoço. $2011 ; 40(1): 1-4$.

\section{Endereço do autor / Dirección del autor / Author's address}

Ivone Rosini

Rua Pedro Vieira Vidal, 208, ap. 801, bloco 1, Pantanal 88040-010, Florianópolis, SC

E-mail:ivonerosini@gmail.com
12 Michelis: moderno dicionário da língua portuguesa. São Paulo: Melhoramentos; 2009.

13 Fernandes SMBA, Medeiros SM, Ribeiro LM. Estresse ocupacional e o mundo do trabalho atual: repercussões na vida cotidiana das enfermeiras. Rev Eletr Enferm [Internet]. 2008 [citado 2010 Ago 26];10(2):414-27. Disponível em: http://www.fen. ufg.br/revista/v10/n2/v10n2a13.htm.

14 Pedroso RA, Celich KLS. Dor: quinto sinal vital, um desafio para o cuidar em enfermagem. Texto \& Contexto Enferm. 2006;15(2):271-84.

15 Araújo IMA, Fernandes AFC. O significado do diagnóstico do câncer de mama para a mulher. Esc Anna Nery Rev Enferm. 2008;12(4):664-71.

16 Guerreiro GP, Zago MMF, Sawada NO, Pinto MH. Relação entre espiritualidade e câncer: perspectiva do cliente. Rev Bras Enferm. 201 1;64(1):53-9.

17 Nascimento TG, Silva SR, Machado ARM. Auto-exame de mama: significado para pacientes em tratamento quimioterápico. Rev Bras Enferm. 2009;62(4):557-561.

18 Silva CP, Dias MAS, Rodrigues AB. Práxis educativa em saúde dos enfermeiros das estratégias saúde da família. Ciênc Saúde Coletiva [Internet]. 2009 [citado 2011 Ago 23];14(5):145362. Disponível em: http://redalyc.uaemex.mx/ pdf/630/63012430015.pdf.

19 Combinato DS, Vecchia, MD, Lopes EG, Manoel RA, Marino HD, Oliveira ACS, et al."Grupos de Conversa”: saúde da pessoa idosa na estratégia saúde da família. Psicol Soc. 2010;22(3):558-68.

20 Correa ACP, Ferreira F, Cruz GSP, Pedrosa ICF. Acesso a serviços de saúde: olhar de usuários de uma unidade de saúde da família. Rev Gaúcha Enferm. 2011;32(3):451-457.

Recebido em: 25.11.2012

Aprovado em: 21.08.2013 